\title{
PERAN KEPUASAN KERJA MEMEDIASI IKLIM ORGANISASI TERHADAP TURNOVER INTENTION
}

\author{
I Made Yuda Dwi Putra ${ }^{1}$ \\ Made Surya Putra ${ }^{2}$ \\ ${ }^{1,2}$ Fakultas Ekonomi dan Bisnis Universitas Udayana (Unud), Bali, Indonesia \\ Email: yudadwiputra10@gmail.com
}

\begin{abstract}
ABSTRAK
Penelitian ini bertujuan mengetahui peran kepuasan kerja memediasi iklim organisasi terhadap turnover intention studi pada Hotel Ramada Bali Sunset Road Kuta. Instrumen yang digunakan pada penelitian ini berupa kuesioner yang terdiri atas pernyataan tentang iklim prganisasi, kepuasan kerja dan turnover intention. Teknik analisis data yang digunakan pada penelitian ini analisis jalur (path analysis). Hasil penelitian menunjukkan bahwa iklim organisasi berpengaruh positif dan signifikan terhadap kepuasan kerja, Iklim organisasi berpengaruh negatifdan signifikan terhadap turnover intention, kepuasan kerja berpengaruh negatif dan signifikan terhadap turnover intention. Saran yang dapat diberikan untuk manajemen Hotel Ramada Bali Sunse Road Kuta untuk tetap menjaga suatu iklim organisasi perusahaan untuk dapat meningkatkan kepuasan kerja karyawannya. Bagi Peneliti selanjutnya disarankan untuk menggunakan variabel lain yang dapat menjadi pemediasi antara iklim organisasi dan turnover intention.
\end{abstract}

Kata Kunci: iklim organisasi, kepuasan kerja, turnover intention

\begin{abstract}
This study aims to determine the role of job satisfaction in mediating the organizational climate toward intention study turnover at Ramada Bali Sunset Road Kuta Hotel. The instrument used in this study is a questionnaire consisting of a statement about the climate of organization, job satisfaction and turnover intention. Data analysis technique used in this research path analysis (path analysis). The results showed that organizational climate had positive and significant effect on job satisfaction, organizational climate had negative and significant effect on turnover intention, job satisfaction had negative and significant effect on turnover intention. Advice can be given to the management of Ramada Bali Sunse Road Kuta Hotel to maintain a corporate organization climate to improve employee job satisfaction. For Researchers, it is suggested to use other variables that can mediate between organizational climate and turnover intention.
\end{abstract}

Keywords: organizational climate, job satisfaction, turnover intention 


\section{PENDAHULUAN}

Sumber Daya Manusia (SDM) di dalam perusahaan berperan sangat penting bagi kelangsungan sebuah perusahaan. Dalam hal ini perusahaan berperan penting untuk tetap menjaga niat karyawan agar tetap bekerja guna mencapai tujuan perusahan tersebut. Karyawan yang merasa tidak betah dengan pekerjaannya dapat mengakibatkan turnover intention, turnover dapat berupa pengunduran diri, perpindahan keluar unit organisasi, pemberhentian, kematian anggota organisasi dan keinginan untuk meninggalkan organisasi. Turnover didahului oleh niat karyawan yang dipicu oleh ketidakpuasan karyawan terhadap pekerjaan serta rendahnya komitmen karyawan untuk mengikatkan diri pada organisasi (Jimad, 2011). Turnover intention merupakan suatu keadaan dimana karyawan memiliki niat yang dilakukan secara sadar untuk mencari suatu pekerjaan lain sebagai alternatif di organisasi yang berbeda dan turnover adalah pergerakan keluarnya tenaga kerja dari tempatnya bekerja (Abdillah, 2012).

Mbah dan Ikemefuna (2012) mengungkapkan bahwa perputaran karyawan yang tidak dikelola dengan baik akan menimbulkan berbagai potensi biaya bagi perusahaan. Biaya yang paling umum dikeluarkan adalah terkait dengan biaya rekrutmen serta biaya pelatihan karyawan yang menyangkut biaya pengadaan wawancara dan seleksi, biaya kompensasi atau tunjangan, tingkat kinerja yang dikorbankan, serta biaya rekrutmen secara langsung (Kumar et al., 2011).

Turnover yang tinggi berbahaya bagi perusahaan dan hal tersebut juga mengurangi efisiensi dan produktivitas organisasi (Joarder et al., 2011). Efek negatif tingginya tingkat turnover karyawan juga dapat menimbulkan pemborosan 
biaya yang cukup besar karena perusahaan harus menginvestasikan biaya untuk melakukan rekrutmen, orientasi, pelatihan, lembur, dan pengawasan (Suryani, 2011).

Tingginya turnover intention juga disebabkan oleh rasa puas atau tidak puasnya karyawan bekerja dalam perusahaan. Menurut Permatasari (2013) ketika karyawan merasakan kepuasan kerja yang rendah, maka menyebabkan komitmen dan loyalitas karyawan menurun serta meningkatkan minat keluar karyawan. Kepuasan kerja telah diakui sebagai topik penelitian yang penting dalam bidang perilaku organisasi karena kepuasan kerja adalah kontributor kunci yang berhubungan dengan hasil kinerja karyawan, seperti produktifitas dan kesejahteraan psikologis karyawan (Cook and Noblet, 2012).

Menurut Pepe (2010)kepuasan kerja memegang peranan penting dalam mengukur tingkat turnover dan secara konsisten ditemukan negatif terkait dengan keinginan keluar. Beberapa faktor yang berkontribusi terhadap kepuasan kerja, yang meliputi iklim organisasi, tunjangan, prestasi, kemandirian, pengakuan, komunikasi, kondisi pekerjaan bekerja, rekan kerja, profesionalisme, upah, hubungan, dukungan atasan, keamanan kerja, fleksibilitas kerja, dan lingkungan tim (Ahmad et al., 2013).Kepuasan kerja merupakan area yang penting dalam organisasi (Awang et al., 2010).Kepuasan kerja adalah reaksi afektif umum atau global yang dimiliki individu terhadap pekerjaan mereka (Javad dan Davood, 2012).

Turnover intention dapat dipengaruhi oleh beberapa faktor, baik dari individu karyawan itu sendiri maupun dari luar individu, yaitu kondisi lingkungan kerja di suatu organisasi atau perusahaan, seperti iklim organisasi. Iklim 
organisasi yang kondusif bagi para karyawan dapat memberikan rasa nyaman dalam bekerja yang berdampak pada loyalitas dan turunnya niat untuk meninggalkan perusahaan. Iklim organisasi sangat berpengaruh terhadap keberlangsungan organisasi tersebut, iklim organisasi adalah kualitas dari sebuah proses interaksi di dalam sebuah organisasi untuk mencapai tujuan yang sudah ditetapkan sehingga anggota organisasi akan melakukan penilaian tentang perusahaan dan membentuk persepsi dalam dirinya tentang iklim organisasi tempatnya bekerja. Pengukuran iklim organisasi menurut Alavi dan Jahandari (2005) dapat diketahui dan diukur melalui persepsi deskriptif individu terhadap karakteristik objektif organisasi yang dilakukan individu pegawai tersebut. Dalam kaitan ini konsep yang digunakan adalah 10 dimensi yaitu hubungan antar personal, manajemen partisipatif, formalisasi, standarisasi, pelatihan, pengembangan, tunjangan finasial, objektifitas, rasionalitas, cakupan kemajuan, supervisi perhatian terhadap kesejahteraan, keselamatan dan keamanan. Susanty (2012) menyatakan bahwa iklim organisasi pada organisasi satu dengan organisasi lain memiliki perbedaan, iklim yang berbeda-beda tersebut mempengaruhi perilaku sumber daya manusia yang berada di dalam organisasi.

Ramada Bali Sunset Road Kuta merupakan salah satu hotel yang terletak di daerah Kuta. Dalam situasi yang dialami oleh industri perhotelan pada umumnya Ramada Bali Sunset Road Kuta juga mengalami masalah pada tingkat turnover karyawan. Hal tersebut terlihat dari data tingkat turnover karyawan Ramada Bali Sunset Road Kuta di tahun 2017 yang disajikan tabel 1 sebagai berikut: 
Tabel 1.

Tingkat Turnover Karyawan Ramada Bali Sunset Road Kuta Tahun 2017

\begin{tabular}{clccccc}
\hline No. & Bulan & $\begin{array}{c}\text { Awal } \\
\text { (Orang) }\end{array}$ & $\begin{array}{c}\text { Masuk } \\
(\text { Orang) }\end{array}$ & $\begin{array}{c}\text { Keluar } \\
(\text { Orang) }\end{array}$ & $\begin{array}{c}\text { Akhir } \\
(\text { Orang) }\end{array}$ & $\begin{array}{c}\text { Turnover } \\
\text { Rate }(\%)\end{array}$ \\
\hline 1 & Januari & 27 & 13 & 8 & 32 & 0,25 \\
2 & Februari & 32 & 22 & 10 & 44 & 0,28 \\
3 & Maret & 44 & 10 & 15 & 39 & 0,38 \\
4 & April & 39 & 25 & 7 & 57 & 0,12 \\
5 & Mei & 57 & 15 & 12 & 60 & 0,20 \\
6 & Juni & 60 & 13 & 6 & 67 & 0,09 \\
7 & Juli & 67 & 8 & 9 & 66 & 0,14 \\
8 & Agustus & 66 & 18 & 6 & 78 & 0,08 \\
9 & September & 78 & 12 & 13 & 77 & 0,17 \\
10 & Oktober & 77 & 15 & 5 & 87 & 0,06 \\
11 & November & 87 & 10 & 7 & 90 & 0,08 \\
12 & Desember & 90 & 5 & 6 & 89 & 0,07 \\
& Jumlah & \multicolumn{1}{c}{ Rata-Rata } & 166 & 104 & & 0,16 \\
\hline
\end{tabular}

Data Tabel 1, Menunjukkan data tingkat turnover karyawan Ramada Bali Sunset Road Kuta pada tahun 2017 yang cenderung fluktuatif dan tertinggi pada bulan Maret. Jika hal tersebut tetap terjadi maka akan berdampak tidak baik bagi perusahaan dan turnover ini disebabkan oleh kurangnya kepuasan kerja karyawan dan rendahnya iklim organisasi perusahaan tersebut.

Turnover intention yang tinggi akan menyebabkan kurang efektifnya perusahaan dalam mengelola kinerja karyawan dan Turnover itu bisa disebabkan karena adanya iklim organisasi yang kurang baik di dalam perusahaan. Iklim organisasi yang baik dapat memberikan rasa nyaman terhadap karyawan dalam bekerja dan dapat meningkatkan suatu kinerja karyawan tersebut untuk mencapai tujuan perusahaan.

Selain iklim organisasi, ada faktor lain yang dapat mempengaruhi terjadinya turnover intention dan berasal dari individu karyawan yaitu kepuasan kerja, sehingga dapat di simpulkan bahwa niat seorang karyawan meninggalkan 
I Made Yuda Dwi Putra, Peran Kepuasan Kerja....

perusahaan akan terjadi apabila karyawan tersebut merasa kondisi lingkungan kerja yang tidak kondusif dan rendahnya kepuasan kerja karyawan tersebut.

Beberapa penelitian yang menguji pengaruh iklim organisasi terhadap turnover intention, yang di antaranya adalah penelitian yang dilakukan oleh Jyoti (2013), Teh (2014) menyatakan bahwa iklim organisasi berpengaruh negatif pada turnover intention. Kustianto dan Iskhak (2015) menemukan hasil bahwa iklim organisasi berpengaruh positif pada kepuasan kerja karyawan. Ahmad et al. (2012) dalam studinya menemukan bahwa kepuasan kerja memiliki pengaruh yang kuat terhadap turnover intention dimana kepuasan kerja berpengaruh negatif terhadap turnover intention.

Penelitian ini bertujuan untuk 1) Untuk menganalisis pengaruh iklim organisasi terhadapkepuasan kerja. 2) Unruk menganalisis pengaruh iklim organisasi terhadap turnover intention. 3) Untuk menganalisis pengaruh kepuasan kerja terhadap turnover intention. 4) Untuk menganalisis peran kepuasan kerja dalam memediasi iklim organisasi terhadap turnover intention.Kegunaan penelitian ini nantinya diharapkan dapat menambah pengetahuan, pengembangan ilmu dalam manajemen sumber daya manusia khususnya menjelaskan faktorfaktor yang mempengaruhi turnover intention. Selain itu, diharapkan memberi manfaat bagi para karyawan perusahaan dalam iklim organisasi yang berdampak langsung dengan situasi kerja yang baik dan kondusif, sebab kepuasan kerja yang tinggi akan menurunkan tingkat turnover intention.

Traditional turnover theory merupakan sebuah teori yang mengamati turnover intention sebagai variabel penyebab turnover yang utama dengan 
mengambil faktor sikap yaitu kepuasan kerja sebagai penyebab perilaku turnover karyawan (Zhao dan Liu, 2010). Selain faktor sikap, kondisi dalam lingkungan organisasi yang tercermin dalam iklim organisasi merupakan faktor lain yang dapat menyebabkan perilaku turnover karyawan. Menurut teori ini, karyawan dengan kepuasan kerja yang tinggi dan iklim organisasi yang baik diyakini tidak mudah untuk meninggalkan pekerjaan mereka. Holtom (2004) dalam Garnita dan Suana (2014) menyatakan bahwa teori traditional turnover ini mendefinisikan dan menjelaskan bagaimana seseorang karyawan merasa kurang puas dengan posisi dalam pekerjaannya, lalu memilih untuk mencari pekerjaan baru, membandingkan posisi pekerjaan mereka saat ini dengan pekerjaan pilihannya, kemudian pergi jika mereka merasa itu merupakan alternatif yang lebih baik dari situasi saat ini yang mereka rasakan.

Abdillah (2012) menyatakan turnover intention merupakan suatu posisi dimana karyawan memiliki keinginan atau niat untuk mencari suatu pekerjaan lain sebagai alternatif di perusahaan yang berbeda. Dampak negatif turnover adalah dampak terhadap biaya organisasi yang berkaitan dengan rekrutmen, seleksi, serta pelatihan personil baru, ditambah lagi turnover dapat menyebabkan penurunan efektivitas dan produktivitas kinerja karyawan karena telah kehilangan rekan kerjanya (Jha, 2010). Menurut Witasari (2009) variabel turnover intention dapat diukur menggunakan indikator yaitu 1) Kecenderungan berfikir untuk meninggalkan organisasi, indikator ini diukur dari sering tidaknya karyawan berfikir untuk keluar dari perusahaan. Keinginan akan mencari pekerjaan pada organisasi lain, indikator ini diukur dari cocok tidaknya karyawan berada di 
lingkungan tempat dia bekerja. 2) Kemungkinan meninggalkan organisasi, indikator ini diukur dengan adanya keinginan karyawan untuk keluar dari perusahaan tempatnya bekerja. 3) Kemungkinan meninggalkan organisasi dalam waktu dekat, indikator ini diukur dari karyawan akan mencari pekerjaan lain tahun depan. 4) Kemungkinan meninggalkan organisasi bila ada kesempatan lebih baik, indikator ini diukur dari evaluasi karyawan untuk menemukan pekerjaan lebih baik di tempat lain

Kepuasan kerja mencerminkan perasaan seseorang terhadap pekerjaannya, ini nampak dalam sikap positif karyawan terhadap pekerjaan dan segala sesuatu yang dihadapi di lingkungan kerjanya. Locke (dalam Turkyimaz et al., 2011) mengatakan bahwa kepuasan kerja merupakan suatu perasaan positif yang timbul dari pegawai sebagai hasil dari pengakuan terhadap pekerjaannya atau pengalamannya dalam bekerja. Menurut Rini dkk. (2013) kepuasan kerja adalah suatu ungkapan perasaan menyenangkan dari hasil persepsi individu dalam rangka menyelesaikan tugas atau memenuhi kebutuhannya dalam memperoleh nilai-nilai kerja yang penting bagi dirinya. Kepuasan dapat menggambarkan perasaan positif dan negatif pegawai dari persepsi terhadap pekerjaan yang dihadapinya, seperti perasaan untuk berprestasi dan meraih kesuksesan dalam pekerjaan, mengimplementasikan kepuasan yang tinggi terhadap pegawai yang merasa senang dan nyaman dengan kondisi lingkungan organisasi dan mendapatkan penghargaan dari jerih payah hasil kerjanya (Aziri, 2011).

Departemen personalia atau manajemen harus senantiasa memonitor kepuasan kerja, karena hal itu mempengaruhi tingkat absensi, perputaran tenaga 
kerja, semangat kerja, keluhan-keluhan dan masalah personalia vital lainnya (Handoko, 2008:193). Menurut Luthans (2006:243) indikator dari kepuasan kerja adalah sebagai berikut. 1) Pekerjaan Itu Sendiri. Dalam hal dimana pekerjaan memberikan tugas yang menarik, kesempatan untuk belajar dan kesempatan untuk menerima tanggung jawab. 2) Gaji. Sejumlah upah yang diterima dan tingkat dimana hal ini biasa dipandang sebagai hal dianggap pantas dibandingkan dengan orang lain dalam organisasi. 3) Kesempatan promosi. Kesempatan untuk maju dalam organisasi. 4) Pengawasan. Kemampuan penyelia untuk memberikan bantuan teknik dan dukungan perilaku. 5) Rekan kerja. Tingkat dimana rekan kerja pandai secara teknis dan mendukung secara sosial.

Putra dkk. (2014) menyatakan bahwa iklim organisasi merupakan kualitas lingkungan internal organisasi yang secara relatif terus berlangsung dialami oleh anggota organisasi, mempengaruhi perilaku mereka dan dapat dilukiskan ke dalam karakteristik atau sifat organisasi. Iklim organisasi merupakan karakteristik yang membedakan satu organisasi dengan organisasi lainnya yang dapat mempengaruhi karyawan sehingga bersedia bekerja (Kusumaningtyas, 2013).

Menurut Cahyono (2014) iklim organisasi disebut juga suasana organisasi adalah serangkaian lingkungan kerja di sekitar tempat kerja yang berpengaruh terhadap perilaku seseorang dalam melaksanakan pekerjaan yang akhirnya menjadikan tujuan organisasi cepat tercapai.Intifada (2013) menyebutkan beberapa dimensi iklim organisasi sebagai berikut: 1) Kepemimpinan. Perilaku atau interaksi seseorang pimpinan dalam mengkoordinasikan dan menggerakan bawahan untuk mencapai tujuan organisasi. 2) Kepercayaan. Adanya sikap saling 
percaya antara karyawan dan pimpinan dengan tetap mengembangkan dan mepertahankan hubungan yang penuh keyakinan dan kepercayaan. 3) Pembuatan keputusan bersama atau dukungan. Para karyawan disemua tingkat organisasi harus diajak komunikasi dan konsultasi mengenai semua masalah dalam semua kebijakan organisasi yang relevan dengan kedudukan mereka dan berperan serta dalam pembuatan keputusan dan penetapan tujuan. 4) Kejujuran. Suasana umum yang diliputi kejujuran dan keterusterangan yang mewarnai hubungan antar karyawan di dalam organisasi, dimana karyawan mampu mengatakan apa yang ada dipikiran mereka. 5) Komunikasi. Karyawan berhak mengetahui akan informasi yang berhubungan dengan tugas dan wewenang mereka. 6) Fleksibilitas atau otonomi. Karyawan memiliki keotonomian dalam tugas pekerjaan sendirisendiri, serta mempunyai kekuatan pada diri sendiri yang mana dapat menerima atau menebak saran dengan pikiran terbuka. Artinya karyawan memiliki kebebasan dalam menyampaikan pendapat. 7) Risiko pekerjaan. Karyawan menyadari akan risiko pekerjaan dengan tetap berkomitmen dan loyal terhadap perusahaan.

Faozi (2014) menemukan hasil penelitian bahwa iklim organisasi berpengaruh pada kepuasan kerja. Afriani (2013) menyimpulkan bahwa iklim organisasi berpengaruh signifikan terhadap kepuasan kerja pegawai, semakin baik iklim dalam organisasi, semakin besar peluang organisasi untuk menciptakan kepuasan kerja yang tinggi. Menurut Kumar (2014) ada hubungan yang positif antara iklim organisasi dan kepuasan kerja karyawan.

Karyawan yang merasa iklim organisasi tempat ia bekerja cukup bagus dan menyenangkan baginya untuk bekerja menyebabkan karyawan tersebut akan 
merasa puas dengan pekerjaannya (Tadampali dkk., 2016). Haryanti (2005) berpendapat bahwa iklim organisasi yang kondusif erat kaitannya dengan kepuasan kerja melalui persepsi pekerjaan itu sendiri. Berdasarkan uraian diatas, maka hipotesis yang diajukan dalam penelitian ini adalah sebagai berikut $\mathrm{H}_{1}$ : Iklim organisasi berpengaruh positif pada kepuasan kerja karyawan.

Beberapa penelitian terkait dilakukan oleh Suliman dan Obaidli (2011), Jyoty (2013), Mamewe (2015), hasil penelitian tersebut menyatakan bahwa persepsi karyawan terhadap iklim organisasi berpengaruh negatif terhadap turnover intention. Menurut Herman dkk. (2014) menyatakan iklim organisasi adalah kondisi lingkungan kerja, baik yang bersifat material/fisik maupun non material/non fisik yang dapat mempengaruhi kinerja karyawan di dalam suatu organisasi.

Penelitian dari Rahimic (2013) menyatakan bahwa iklim organisasi dan kepuasan kerja adalah dua konstruk yang berbeda, tetapi mereka berdua mempengaruhi kinerja karyawan dan niat untuk meninggalkan. Wirawan (2009:122) mengungkapkan iklim organisasi adalah persepsi anggota organisasi (secara individual atau kelompok) dan mereka secara tetap beruhubungan dengan organisasi mengenai yang ada atau terjadi di lingkungan internal organisasi secara rutin, yang mempengaruhi sikap dan perilaku organisasi yang kemudian menentukan kinerja organisasi. Berdasarkan uraian diatas, maka hipotesis yang diajukan dalam penelitian ini adalah sebagai berikut.

$\mathrm{H}_{2}$ : Iklim organisasi berpengaruh negatif pada turnover intention.

Jaramillo et al. (2006) berpendapat bahwa kepuasan kerja yang diperoleh oleh seseorang dapat menurunkan keinginannya untuk meninggalkan 
perusahaannya. Penelitian yang dilakukan oleh Salleh et al. (2012) menyatakan bahwa semua aspek kepuasan kerja yang meliputi promosi, pekerjaan itu sendiri, serta supervise kecuali rekan kerja berpengaruh negatif terhadap turnover intention. Pembuktian pengaruh negatif yang dilakukan peneliti berupaya untuk menjelaskan bahwa semakin tinggi kepuasan kerja maka niat keluar karyawan dari perusahaan cenderung rendah (Andini, 2006)

Hasil penelitian yang dilakukan Ali (2008), Witasari (2009), Yucel (2012), Islam et al. (2012) dan Jyoti (2013) menyatakan bahwa kepuasan kerja memiliki pengaruh negatif terhadap turnover intention. Hasil penelitian Indrayanti dan I Gede Riana (2016),didukung pula oleh penelitian Ratna Sari dkk. (2015), serta Mahdi et al. (2012) yang menyatakan adanya pengaruh negatif antara kepuasan kerja dengan turnover intention, dimana karyawan yang mencapai kepuasan kerja akan berusaha untuk tetap berada di dalam perusahaan. Pernyataan tersebut diperkuat oleh hasil temuan dari Han dan Jekel (2011) dan Kabungaidze et al. (2013) yang menyatakan, bahwa karyawan yang tidak puas dengan pekerjaan mereka, akan mengalami sikap negatif terhadap pekerjaan mereka dan sikap positif terhadap turnover intention, jadi semakin tinggi tingkat kepuasan kerja karyawan maka semakin rendah tingkat turnover intention karyawan. Berdasarkan uraian diatas, maka hipotesis yang diajukan dalam penelitian ini adalah sebagai berikut

$\mathrm{H}_{3}$ : Kepuasan kerja berpengaruh negatif pada turnover intention.

Penelitian yang dilakukan Jyoti (2013) menyatakan bahwa kepuasan kerja dapat memediasi pengaruh iklim organisasi terhadap turnover intention. Ajzen dan Fishbein (1975) dalam Mowen dan Minor (2005:142) menyatakan bahwa niat 
seseorang sangat bergantung pada sikap dan norma subjektif atas perilaku tersebut. Sikap yang dimaksud adalah kepuasan kerja karyawan dan norma subjektif merupakan iklim dari suatu organisasi, niat dari seorang karyawan meninggalkan suatu perusahaan dapat dipengaruhi oleh iklim organisasi dan tingkat kepuasan kerja. Berdasarkan uraian diatas, maka hipotesis yang diajukan dalam penelitian ini adalah sebagai berikut.

$\mathrm{H}_{4}$ : Kepuasan kerja memediasi pengaruh iklim organisasi pada turnover intention.

\section{METODOLOGI PENELITIAN}

Desain penelitian ini berbentuk asosiatif, Variabel yang diteliti dalam penelitian ini adalah iklim organisasi (X) sebagai variabel bebas, kepuasan kerja (M) sebagai variabel mediasi, serta turnover intention (Y) sebagai variabel terikat.Penelitian ini bertempat pada Hotel Ramada Bali Sunset Road Kuta yang beralamat di Jalan Sunset Road No.9 Kuta, Badung, Bali. Penelitian ini dilakukan di Hotel Ramada Bali Sunset Road Kuta karena ditemukan adanya masalah yang terkait dengan turnover intention.

Variabel yang digunakan dalam penelitian ini terdiri dari tiga jenis variabel yaitu variabel independen, variabel dependen, dan variabel mediasi.Variabel independen dalam penelitian ini adalah Iklim Organisasi (X), variabel dependen dalam penelitian ini adalah Turnover Intention (Y), serta variabel mediasi dalam penelitian ini adalah Kepuasan Kerja (M).Sumber data yang digunakan dalam penelitian ini adalah data primer, yaitu data yang diperoleh secara langsung dari sumber asli atau pihak pertama melalui kuesioner penelitian. 
Menurut Wirawan (2002), sampel adalah sebagian dari populasi yang karakteristiknya hendak diselidiki. Sampel yang diambil dalam penelitian yaitu sebanyak 73 karyawan yang diperoleh melalui pendekatan Slovin agar dapat mewakili populasi secara keseluruhan dengan tingkat nilai kritis sebesar 5\% $(0,05)$, dengan pendekatan ini diharapkan dapat lebih efisien dalam penyebaran kuisioner sehingga tingkat kesalahan atau tidak terwakilkannya responden dapat diminimalisir. Rumus Slovin yang digunakan adalah sebagai berikut.

$$
\begin{aligned}
& r=\mathrm{N} / 1+\mathrm{Ne}^{2} \\
& \pi=89 / 1+89(0,05)^{2} \\
& \pi=73 \text { karyawan Hotel Ramada Bali Sunset Road. }
\end{aligned}
$$

Analisis jalur atau path analysismerupakan metode analisis data yang digunakan dalam penelitian ini. Kerangka penelitian yang dapat dikembangkan berdasarkan teknik analisis data yang digunakan.

Persamaan Sub-struktural 1

$$
\mathrm{M}=\beta_{1} \mathrm{X}_{1}+\mathrm{e}_{1}
$$

Persamaan Sub-struktural 2

$$
\mathrm{Y}=\beta_{1} \mathrm{X}_{2}+\beta_{1} \mathrm{M}+\varepsilon_{2}
$$

Keterangan:

$$
\begin{array}{ll}
\mathrm{X} & =\text { Iklim organisasi } \\
\mathrm{M} & =\text { Kepuasan kerja } \\
\mathrm{Y} & =\text { Turnover intention } \\
\beta_{1-} \beta_{2} & =\text { Koefisien regresi variabel } \\
\mathrm{e} & =\text { error }
\end{array}
$$

Pengujian hipotesis mediasi dapat dilakukan dengan Uji Sobel (Sobel Test). Uji sobel digunakan untuk menguji kekuatan pengaruh tidak langsung variabel 
iklim organisasi $(\mathrm{X})$ ke variabel turnover intention $(\mathrm{Y})$ melalui variabel kepuasan kerja(M). Pengaruh tidak langsung iklim organisasi (X) terhadap variabel turnover intention (Y) melalui variabel kepuasan kerja (M) dihitung dengan mengalikan koefisien jalur X terhadap M (a) dengan koefisien jalur M terhadap Y (b) atau ab. Standard error koefisien a dan b ditulis dengan $S_{a}$ dan $S_{b}$, besarnya standard error tidak langsung (indirect effect) $\mathrm{S}_{\mathrm{ab} 1}$ dihitung dengan rumus dibawah ini:

$$
\mathrm{Sab}=\sqrt{b^{2} S a^{2}+a^{2} S b^{2}+S a^{2} S b^{2}}
$$

Untuk menguji signifikansi pengaruh tidak langsung, maka dapat dilakukan dengan menghitung $\mathrm{t}$ dari koefisien ab dengan rumus sebagai berikut:

$$
\mathrm{Z}=\frac{a b}{S a b}
$$

Untuk mengetahui pengambilan keputusan uji hipotesa, maka dilakukan dengan cara membandingkan p- value dan alpha $(0,05)$ atau membandingkan hitung dengan $\mathrm{z}$ tabel, yang menggunakan taraf nyata 5 persen dengan daerah kritis -2,6847 dengan ketenuan sebagai berikut:

$\mathrm{Z}$ hitung $\leq \mathrm{z}$ tabel, maka $\mathrm{H}_{0}$ diterima, berarti kepuasan kerja(M) bukan sebagai variabel mediasi. $\mathrm{z}$ hitung $>\mathrm{z}$ tabel, maka $\mathrm{H}_{0}$ ditolak, berarti kepuasan kerja(M) merupakan variabel mediasi (Utama, 2014:167).

\section{HASIL PENELITIAN DAN PEMBAHASAN}

Data karakteristik responden adalah data responden yang dikumpulkan untuk mengetahui profil responden penelitian. Responden dalam penelitian ini meru[akan karyawan Hotel Ramada Bali Sunset Road Kuta, dimana dalam 
peneliyian ini sampel yang digunakan sebanyak 73 orang. Berdasarkan hasil penelitian yang dilakukan terhadap karyawan Hotel Ramada Bali Sunset Road Kuta dapat diketahui karakteristik respondennya meliputi jenis kelamin, usia dan pendidikan terakhir yang dijelaskan pada Tabel 2.

Tabel 2.

Karakteristik Responden Penelitian Menurut Umur, Jenis Kelamin, dan Pendidikan Terakhir

\begin{tabular}{|c|c|c|c|c|}
\hline No & Variabel & Klasifikasi & Jumlah & Presentase \\
\hline \multirow[t]{3}{*}{1} & Jenis Kelamin & Pria & 50 & 68,5 \\
\hline & & Wanita & 23 & 31,5 \\
\hline & & & 73 & 100 \\
\hline \multirow[t]{6}{*}{2} & Usia & 21-25 tahun & 37 & 50,7 \\
\hline & & 26-30 tahun & 17 & 23,3 \\
\hline & & 31-35 tahun & 9 & 12,3 \\
\hline & & $36-40$ tahun & 2 & 2,74 \\
\hline & & 41-45 tahun & 8 & 11 \\
\hline & & & 73 & 100 \\
\hline \multirow[t]{7}{*}{3} & Pendidikan Terakhir & SMA/SMK & 20 & 27,4 \\
\hline & & D1 & 13 & 17,8 \\
\hline & & $\mathrm{D} 2$ & - & - \\
\hline & & D3 & 18 & 24,7 \\
\hline & & D4 & 9 & 12,3 \\
\hline & & S1 & 13 & 17,8 \\
\hline & $\mathbf{J u}$ & & 73 & 100 \\
\hline
\end{tabular}

Sumber: Data diolah, 2018

Hasil di lapangan menunjukkan bahwa sebagian besar responden berada diantara umur 21-25 tahun yaitu sebanyak 37 orang responden atau 50.7 persen. Usia tersebut merupakan usia produktif untuk bekerja dengan aktif diperusahaan. Kemudian dari segi jenis kelamin tidak terlalu menunjukkan gap, diketahui bahwa jumlah responden laki-laki lebih besar dibandingkan dengan responden perempuan, dimana jumlah responden laki-laki sebanyak 50 orang responden dan responden perempuan sebanyak 23 orang. Perbedaan jenis kelamin tidak begitu mempengaruhi. Berdasarkan Tabel 2, diketahui jumlah responden dengan tingkat 
pendidikan SMA/SMK lebih banyak dibandingkan dengan tingkat pendidikan lain, yaitu sebesar 20 orang responden sedangkan jumlah responden yang paling sedikit yaitu tingkat pendidikan D4 dengan jumlah 9 orang responden.

Berdasarkan hasil analisis jalur substruktur 1, nilai $\beta_{1}$ adalah sejumlah 0,800 berarti iklim organisasi yang berpengaruh positif terhadap kepuasan kerja, yang menunjukkan bahwa apabila variabel iklim organisasimeningkat maka kepuasan kerja pada Hotel Ramada Bali Sunset Road juga akan meningkat.Hasil analisis jalur substruktur 2 menunjukkan nilai $\beta 2$ sejumlah $-0,403$ berarti iklim organisai berpengaruh negatif terhadap turnover intention yang berarti apabila variabel iklim organisasimenurun maka meningkatkan variabel turnover intention. Nilai $\beta_{3}$ seumlah $-0,347$ berarti kepuasan kerjaberpengaruh negatif terhadap turnover intention, hal ini berarti apabila variabel kepuasan kerja menurun maka variabel turnover intention pada Hotel Ramada Bali Sunset Road Kuta akan meningkat.

Berdasarkan hasil perhitungan pengaruh error (Pei), maka hasil pengaruh error $\left(\mathrm{Pe}_{1}\right)$ yang didapat sebanyak 0,6 dan pengaruh error $\left(\mathrm{Pe}_{2}\right)$ sebanyak 0,703 . Setelah menganalisis $\mathrm{e}_{1}$ dan $\mathrm{e}_{2}$, maka didapat perhitungan koefisien determinasi total sebesar 0,822 memiliki arti bahwa 82,2 persen variabel turnover intention dipengaruhi oleh variabel iklim organisasi dan kepuasan kerja, sisanya sebesar 17,8 persen dijelaskan oleh faktor lain di luar model yang dibentuk.

Untuk memahami pengaruh total (total effect) dapat dilakukan dengan menambah pengaruh langsung iklim organisasi terhadap turnover intention lalu mengalikan pengaruh langsung iklim organisasi terhadap kepuasan kerja dengan pengaruh langsung kepuasan kerja terhadap turnover intention. 
Total pengaruh variabel $\mathrm{X}$ terhadap $\mathrm{Y}$ melalui $\mathrm{M}$ dapat dirumuskan sebagai berikut:

$$
\begin{aligned}
\text { Total effect } & =-0,403+(0,800 \times-0,347) \\
& =-0,681
\end{aligned}
$$

Berdasarkan hasil pengolahan data diperoleh nilai $\mathrm{F}$ sebesar 35,896 dengan nilai $(\mathrm{sig})=0,000$. oleh karena nilai sig $0,000<0,05$, maka dapat disimpulkan bahwa $\mathrm{H}_{0}$ ditolak dan $\mathrm{H}_{1}$ diterima. Artinya bahwa variabel iklim organisasi dan kepuasan kerja berpengaruh secara simultan dan signifikan terhadap turnover intention.

Berdasarkan hasil pengujian hasil hipotesis pertama, maka $\mathrm{H}_{1}$ diperoleh nilai probabilitas (sig) 0,000 dengan nilai koefisien beta sebesar 0,800 dan nilai $\mathrm{t}$ sebesar 11,243. Tingkat signifikansi variabel sebesar 0,000 yang berarti lebih kecil dari taraf nyata sebesar 0,05 , maka hal ini dapat diartikan bahwa $\mathrm{H}_{0}$ ditolak dan $\mathrm{H}_{1}$ diterima. Hasil ini mempunyai arti bahwa iklim organisasisecara positif dan signifikan berpengaruh terhadap kepuasan kerja. Hasil penelitian ini didukung oleh pendapat Suhanto (2009) yang menyatakan bahwa iklim organisasi mempunyai pengaruh langsung maupun tidak langsung terhadap kepuasan kerja.

Faozi (2014) menemukan hasil penelitian bahwa iklim organisasi berpengaruh pada kepuasan kerja. Afriani (2013) menyimpulkan bahwa iklim organisasi berpengaruh signifikan terhadap kepuasan kerja pegawai, semakin baik iklim dalam organisasi, semakin besar peluang organisasi untuk menciptakan kepuasan kerja yang tinggi. Menurut Kumar (2014) ada hubungan yang positif antara iklim organisasi dan kepuasan kerja karyawan. Karyawan yang merasa iklim organisasi tempat ia bekerja cukup bagus dan menyenangkan baginya untuk 
bekerja menyebabkan karyawan tersebut akan merasa puas dengan pekerjaannya (Tadampali dkk., 2016). Haryanti (2005) berpendapat bahwa iklim organisasi yang kondusif erat kaitannya dengan kepuasan kerja melalui persepsi pekerjaan itu sendiri.

Berdasarkan hasil hipotesis kedua $\mathrm{H}_{2}$ diperoleh nilai probabilitas (sig) sebesar 0,005 dengan nilai koefisien beta $-0,403$ serta nilai t sebesar -2,878. Dengan nilai signifikasi sebesar 0,005 yang lebih kecil dari taraf nyata 0,05 , maka hal ini dapat diartikan $\mathrm{H}_{0}$ ditolak dan $\mathrm{H}_{1}$ diterima. Hasil ini mempunyai arti bahwa iklim organisasi berpengaruh secara positif dan signifikan terhadap turnover intention. Hasil penelitian ini didukung oleh penelitian sebelumnya oleh Suliman dan Obaidli (2011), Jyoty (2013), dan Mamewe (2015) yang menemukan adanya pengaruh negatif pada variabel iklim organisasi terhadap turnover intention.

Beberapa penelitian terkait dilakukan oleh Suliman dan Obaidli (2011), Jyoty (2013), Mamewe (2015), hasil penelitian tersebut menyatakan bahwa persepsi karyawan terhadap iklim organisasi berpengaruh negatif terhadap turnover intention. Menurut Herman dkk. (2014) menyatakan iklim organisasi adalah kondisi lingkungan kerja, baik yang bersifat material/fisik maupun non material/non fisik yang dapat mempengaruhi kinerja karyawan di dalam suatu organisasi.

Penelitian dari Rahimic (2013) menyatakan bahwa iklim organisasi dan kepuasan kerja adalah dua konstruk yang berbeda, tetapi mereka berdua mempengaruhi kinerja karyawan dan niat untuk meninggalkan. Wirawan (2009:122) mengungkapkan iklim organisasi adalah persepsi anggota organisasi (secara individual atau kelompok) dan mereka secara tetap beruhubungan dengan 
organisasi mengenai yang ada atau terjadi di lingkungan internal organisasi secara rutin, yang mempengaruhi sikap dan perilaku organisasi yang kemudian menentukan kinerja organisasi.

Berdasarkan hasil pengujian hipotesis ketiga $\mathrm{H}_{3}$ diperoleh nilai probabilitas (sig) sebesar 0,016 dengan nilai koefisien beta sebesar -0,347 serta nilai t sebesar 2.476. Dengan nilai signifikansi sebesar 0,016 yang lebih kecil dibandingkan nilai taraf nyata sebesar 0,05 , maka hal ini dapat diartikan bahwa $\mathrm{H}_{0}$ ditolak dan $\mathrm{H}_{1}$ diterima. Hasil ini mempunyai arti bahwa kepuasan kerjaberpengaruh secara negatif dan signifikan terhadap turnover intention.Hasil penelitian ini sesuai dengan traditional turnover theory yang menyatakan bahwa semakin tinggi tingkat kepuasan kerja, maka keinginan untuk meninggalkan perusahaan akan semakin rendah. Hasil temuan ini juga sesuai dengan penelitian Kurniawan (2009), Handaru dan Nailul (2012), dan Salleh et al. (2012) yang menyatakan bahwa kepuasan kerja behubungan negatif dengan turnover intention.

Jaramillo et al. (2006) berpendapat bahwa kepuasan kerja yang diperoleh oleh seseorang dapat menurunkan keinginannya untuk meninggalkan perusahaannya. Penelitian yang dilakukan oleh Salleh et al. (2012) menyatakan bahwa semua aspek kepuasan kerja yang meliputi promosi, pekerjaan itu sendiri, serta supervise kecuali rekan kerja berpengaruh negatif terhadap turnover intention. Pembuktian pengaruh negatif yang dilakukan peneliti berupaya untuk menjelaskan bahwa semakin tinggi kepuasan kerja maka niat keluar karyawan dari perusahaan cenderung rendah (Andini, 2006)

Hasil penelitian yang dilakukan Ali (2008), Witasari (2009), Yucel (2012), Islam et al. (2012) dan Jyoti (2013) menyatakan bahwa kepuasan kerja memiliki 
pengaruh negatif terhadap turnover intention. Hasil penelitian Indrayanti dan I Gede Riana (2016) didukung pula oleh penelitian Ratna Sari dkk. (2015), serta Mahdi et al. (2012) yang menyatakan adanya pengaruh negatif antara kepuasan kerja dengan turnover intention, dimana karyawan yang mencapai kepuasan kerja akan berusaha untuk tetap berada di dalam perusahaan. Pernyataan tersebut diperkuat oleh hasil temuan dari Han dan Jekel (2011) dan Kabungaidze et al. (2013) yang menyatakan, bahwa karyawan yang tidak puas dengan pekerjaan mereka, akan mengalami sikap negatif terhadap pekerjaan mereka dan sikap positif terhadap turnover intention, jadi semakin tinggi tingkat kepuasan kerja karyawan maka semakin rendah tingkat turnover intention karyawan.

Berdasarkan hasil pengujian hipotesis keempat $\mathrm{H}_{4}$ diperoleh hasil nilai $\mathrm{Z}$ sebesar -2,6847 yang lebih besar dari nilai Z tabel sebesar -1,96dengan tingkat signifikansi 0,000 yang lebih kecil dari 0,05., hal ini menunjukkan bahwa $\mathrm{H}_{4}$ dapat diterima, sehingga dapat diartikan bahwa kepuasan kerjamampu memediasi pengaruh iklim organisasi terhadap.turnover intention. Hasil penelitian ini juga didukung oleh pendapat dari Teh (2014) mengenai pengaruh iklim organisasi terhadap turnover intention dan kepuasan kerja sebagai variabel mediasi memiliki dampak negatif terhadap turnover intention.Penelitian yang dilakukan Jyoti (2013) menyatakan bahwa kepuasan kerja dapat memediasi pengaruh iklim organisasi terhadap turnover intention. Ajzen dan Fishbein (1975) dalam Mowen dan Minor (2005:142) menyatakan bahwa niat seseorang sangat bergantung pada sikap dan norma subjektif atas perilaku tersebut. Sikap yang dimaksud adalah kepuasan kerja karyawan dan norma subjektif merupakan iklim dari suatu 
organisasi, niat dari seorang karyawan meninggalkan suatu perusahaan dapat dipengaruhi oleh iklim organisasi dan tingkat kepuasan kerja.

Hasil penelitian ini memberikan sebuah implikasi kepada Hotel Ramada Bali Sunset Road Kuta mengenai bagaimana pentingnya iklim organisasi dan kepuasan kerja dapat memengaruhi turnover intention pada karyawan Hotel Ramada Bali Sunset Road Kuta. Hasil yang diperoleh dari penelitian ini menunjukkan hubungan secara langsung antar variabel, salah satunya adalah variabel iklim organisasi terhadap kepuasan kerja. Hal ini menunjukkan bahwa semakin baik suatu iklim organisasi pada Hotel Ramada Bali Sunset Road Kuta, maka akan berdampak baik juga bagi kepuasan kerja dari Hotel Ramada Bali Sunset Road Kuta, selanjutnya terdapat hubungan secara langsung antar variabelkepuasan kerja terhadap turnover intention, hal ini dapat diartikan bahwa semakin baik kepuasan kerja karyawandari Hotel Ramada Bali Sunset Road Kuta maka akan semakin menurunkan turnover intention karyawan pada Hotel Ramada Bali Sunset Road Kuta. Selain itu, terdapat juga pengaruh langsung pada variabel iklim organiasasi terhadap turnover intention. Ini dapat diartikan bahwa iklim organisasi juga memengaruhi turnover intention karyawan. Implikasi penelitian ini dapat menggambarkan bahwa iklim organisasi dan kepuasan kerja yang baik sangat memengaruhi turnover intention karyawan pada Hotel Ramada Bali Sunset Road Kuta. 


\section{SIMPULAN DAN SARAN}

Iklim organisasiberpengaruh positif dan signifikan terhadap kepuasan kerja, hal ini berarti bahwa semakin baik iklim organisasi di Hotel Ramada Bali Sunset Road Kuta maka akan meningkatkan kepuasan kerja karyawan itu sendiri. Iklim organisasi berpengaruh secara negatif dan signifikan terhadap turnover intention, hal ini menunjukkan bahwa dengan membaiknya persepsi karyawan mengenai iklim organisasi maka akan menurunkan turnover intention karyawan pada Hotel Ramada Bali Sunset Road Kuta.

Kepuasan kerja berpengaruh negatif dan signifikan terhadap turnover intention, hal ini menunjukkan bahwa dengan membaiknya persepsi karyawan mengenai kepuasan kerja maka akan menurunkan turnover intention karyawan pada Hotel Ramada Bali Sunset Road Kuta. Kepuasan kerja memediasi pengaruh iklim organiasasi terhadap turnover intention.

Penelitian ini masih memiliki keterbatasan, sehingga masih perlu untuk disempurnakan lagi bila ada yang harus diperbaiki dan berdasarkan penelitian diatas maka dapat diambil saran-saran yaitu untuk meningkatkan tingkat rata-rata iklim organisasi maka perusahaan Hotel Ramada Bali Sunset Road Kutadiharapkan dapat meningkatkan rasa percaya antara karyawan dengan pimpinan dan karyawan ikut diajak berkonsultasi atas masalah yang dihadapi oleh perusahaan. Selanjutnya, untuk meningkatkan tingkat rata-rata kepuasan kerja maka perusahaan Hotel Ramada Bali Sunset Road Kuta diharapkan agar menaikkan upah gaji yang diberikan kepada karyawan agar dirasa lebih pantas. 
Untuk mengurangi rata-rata tingkat turnover intention maka perusahaan Hotel Ramada Bali Sunset Road Kuta diharapkan dapat berkembang agar bisa bersaing bahkan lebih unggul dari perusahaan lain untuk menutup kemungkinan karyawannya keluar bila ada kesempatan yang lebih baik. Kepada peneliti selanjutnya disarankan untuk menggunakan variabel lain yang dapat menjadi pemediasi antara iklim organisasi dan turnover intention.

\section{REFERENSI}

Abdillah, Fuad. (2012). Hubungan Kohevitas Kelompok Dengan Intensi Turnover Pada Karyawan. Journal of Social and Industrial Psychology. 1(2), hal.5258.

Afriani, Fitri. (2013). Pengaruh Iklim Organisasi terhadap Kepuasan Kerja Pegawai pada Kantor Kecamatan Kepenuhan Hulu. Jurnal Mahasiswa Prodi S1 Manajemen. 1(1), hal.1-23

Ahmad Bashir., Muhammad Shahid., Huma Zill E., and Haider Sajjad. (2012). Turnover Intention: An HRM Issue in Textile Sector. Interdisciplinary Journal Of Contemporary Reseacrh In Business. 3(12), pp.125-130

Ahmad, Abd Rahman., Mohd Nazir Mohd Adi., Haris Md Noor., Abdul Ghafar Abdul Rahman., \& Tan Yushuang. 2013. The Influence of Leadership Style on Job Satisfaction among Nurses. Asian Social Science. 9(9), pp. 1911-2025.

Alavi, Hamid Reza dan Ramazan Jahandari, (2005). The Organizational Climate of Kerman Shahid Bahonar University, Public Personel Management. 34 (3), pp. 247

Andini, Rita. (2006). Analisis Pengaruh Kepuasan Gaji, Kepuasan Kerja, Komitmen Organisasional terhadap Turnover Intention: Studi Kasus pada Rumah Sakit Roemani Muhamadyah Semarang. Jurnal Manajemen Fakultas Ekonomi Universitas Pandanaran.8(16). hal.1-10

Awang, Zainudin., Junaidah Hanim Ahmad., and Nazmi Mohamed Zin. (2010). Modelling Job Satisfaction And Work Commitment Among Lecturers: A Case Of UiTM Kelantan. Journal of Statistical Modelling and Analytics. 1(2), pp.45-59.

Aziri, B. (2011). Job Satisfaction: A Literature Review. Management Research and Practice. 3,(4), pp.77-86 
Cahyono, Eko Aprihadi. (2014). Pengaruh Gaya Kepemimpinan, Motivasi Kerja dan Iklim Organisasi Terhadap Prestasi Kerja Karyawan Bagian Engeneering Pada PT. Arabikatama Khatulistiwa Fishing Industry Denpasar. E-Jurnal Manajemen Universitas Udayana. 3(9), hal.2784-2798

Cook, Kay, and Andrew Noblet. (2012). Job Satisfaction And "Welfare To Work": Is Any Job A Good Job For Australian Single Mothers?. Australian Journal Of Social. 47(2) pp. 203

Faozi, Mohamad. (2014). Pengaruh Komitmen Organisasi, Kompensasi, Budaya Kerja, Motivasi dan Iklim Organisasi terhadap Kepuasan Kerja Guru SMP Negeri dan Swasta Di Kecamatan Tarub Kabupaten Tegal. Jurnal Magister Manajemen UDINUS Semarang. 1(1), hal. 1-14

Garnita, Ni Made Ayu dan Suana, I Wayan. (2014). PengaruhJob Embeddednessdan Kepuasan Kerja Terhadap Turnover Intention. EJournal Manajemen Universitas Udayana. 3(9), hal.2767-2768

Han, Guohong, and Marc Jekel. (2011). The Meditiating Role of Job Satisfaction Between Leader Member Exchange and Turnover Intentions. Journal Of Nursing Management. 19(1), pp.41-49.

Handaru, Agung W dan Nailul Muna. (2012). Pengaruh Kepuasan Gaji dan Komitmen Organisasi Terhadap Intensi Turnover pada Divisi PT. Jamsostek. Jurnal Riset Manajemen Sains Indonesia. 3(1), hal.1-9

Handoko, T. H. (2008). Manajemen Personalia dan Sumber Daya Manusia. Yogyakarta: BPFE.

Haryanti, Endang. (2005). Analisis Pengaruh Gaya Kepemimpinan Dan Iklim Organisasi Terhadap Kepuasan Kerja dan Kinerja Pegawai Kantor Kecamatan Gayamsari Pemkot Semarang. Tesis. Program Pasca Sarjana Magister Manajemen Universitas Diponegoro.

Herman, Djailani AR., dan Sakdiah Ibrahim. (2014). Pengaruh Iklim Organisasi dan Kepuasan Kerja Terhadap Kinerja Guru. Jurnal Administrasi Pendidikan Pascasarjana Universitas Syiah Kuala. 4(2), hal. 160.

Indrayanti, Desak Putu., dan I Gede Riana. (2016). Pengaruh Kepuasan Kerja Terhadap Turnover Intention Melalui Mediasi Komitmen Organisasional Pada PT. Ciomas Adisatwa Di Denpasar. E-Journal Manajamen Unud. 5(5), hal.2727-2755.

Intifada, Khoirina Yuniarti. (2013). Analisis Pengaruh Gaya Kepemimpinan dan Iklim Organisasi terhadap Peningkatan Kinerja Guru melalui Kepuasan Kerja Guru pada SMA Negeri 3 Jember. Skripsi.

Islam, Talat, S.R. Khan, Muhammad Amir, and U.N.U. Ahmad. (2012). Turnover Intention: The Influence of Organizational Learning Culture and Multi foci 
Citizenhip Behaviors. Middle-East Journal of Scientific Research. 12(5), pp.650-661.

Jaramillo, Fernando, Jay Parakash Mulki, and Paul Solomon, (2006). The Role of Ethical Climate on Salesperson Role Stress, Job Attitudes, Turnover Intention, and Job Performance, Journal of Personal Selling \& Sales Management. 26(3), pp.271-282.

Javad, Eslami and Davood Gharakhani. (2012). Organizational Commitment and Job Satisfaction. ARPN Journal of Science and Technology. 2(2), pp.8591.

Jha, Shaweta. (2010). Determinant of Employee Turnover Intentions: A Review. Indian Lecture Review. 1(1), pp.1-22.

Jimad, Habibullah. (2011). Kepuasan Kerja, Komitmen Organisasi, Dan Intensi Turnover, Jurnal Bisnis \& Manajemen, Jurusan Manajemen Fakultas Ekonomi Universitas Lampung, Bandar Lampung.7(2), hal.155-163.

Joarder, Mohd H. R., Sharif, Mohmad Yazam and Ahmmed, Kawsar. (2011). Mediating Role of Affective Commitment in HRM Practices and Turnover intention Relationship: A Study in a Developing Context. Business and Economics Research Journal. 2(4), pp.135-158.

Jyoti Jeevan. (2013). Impact of Organizational Climate on Job Satisfaction, Job Commitment and Intention to Leave: An Empirical Model. Journal of Business Theory and Practice. 1(1), pp.66-82.

Kabungaidze, Trust, Nomakholwa Mahlatshana., and Hlanganipai Ngirande. (2013). The Impact Of Job Satisfaction and Some Demographic Variables on Employee Turnover Intentions. International Journal Of Business Administration. 4(1), pp.53-65.

Kumar, R., Charles, R., and Peter Y. (2011). A Study on Turnover Intention in Fast Food Industry: Employees' Fit to the Organizational Culture and the Important of their Commitment. International Journal of Academic Research in Business and Social Sciences. 2(5), pp.9-42.

Kumar, Rakesh. (2014). Impact Organisational Climate On Job Satisfaction: A Study of Bharti Airtel India Limited In Shimla Zonal Office. International Journal of Development Research. 4(5), pp.958-964.

Kustianto, Fery dan Ahmad Abidin Iskhak. (2015). Pengaruh Iklim Organisasi Terhadap Komitmen Karyawan dengan Kepuasan Kerja sebagai Variabel Intervening pada PT. Garam (PERSERO). Jurnal Ilmu Manajemen MAGISTRA.1(1) hal.42-55.

Kurniawan, Andri. (2009). Pengaruh Kepuasan Kerja Karyawan Terhadap Intensi Turnover Melalui Komitmen Organisasi Karyawan ( Studi pada Karyawan 
PT. Hero Sakti Motor Malang). Skripsi Jurusan Manajemen Fakultas Ekonomi Universitas Negeri Malang

Kusumaningtyas, Amiartuti, (2013). Pengaruh Iklim Organisasi dan Kepemimpinan Terhadap Kepuasan Kerja Karyawan PT. Persada Jaya Indonesia di Kabupaten Sidoarjo. Jurnal Ekonomi dan Manajemen Bisnis. 4(1), hal.107-120.

Luthans, Fred. (2006). Perilaku Organisasi. Edisi kesepuluh. Yogyakarta: PT. Andi.

Mahdi, Ahmad Faisal., Mohamad Zaid Mohd Zin, Mohd Roslan Mohd Nor, Ahamad Asmadi Sakat and Abang Sulaiman Abang Naim.2012.The Relationship Between Job Satisfaction and Turnover Intention. American Journal of Applied Sciences. 9(9), pp.1518-1526.

Mamewe, Lanny. (2015). Stres Kerja dan Iklim Organisasi Serta Pengaruhnya Terhadap Turnover Intention Dengan Kepuasan Kerja Sebagai Variabel Pemediasi. Jurnal Riset Bisnis dan Manajemen. 3(4), hal.328-371.

Mbah, S. E. and Ikemefuna C. O. (2012). Job Satisfaction and Employees Turnover Intentions in total Nigeria plc. in Lagos State. International Journal of Humanities and Social Science. 2(14), pp.275-287.

Mowen, John, C dan Michael Minor. (2002). Perilaku Konsumen. Jilid Kedua. Jakarta: Erlangga.

Permatasari, Devi. (2013). Faktor-Faktor Yang Mempengaruhi Keinginan Berpindah Auditor (Studi Empiris pada Kantor Akuntan Publik di Jawa Tengah dan Daerah Istimewa Yogjakarta). Jurnal Dinamika Akuntansi. 5 (2), hal.121-134.

Pepe, Michael. (2010). The Impact Of Extrinsic Motivational Dissatifiers On Employee Level Of Job Satisfaction And Commitment Resulting In The Intent To Turnover. Journal of Business \& Economics Research. 8(9), pp. 99-108.

Putra, Agung Utomo., Endang Siti Astuti dan Djamhur Hamid. (2014). Pengaruh Iklim Organisasi terhadap Eustress dan Kepuasan Kerja Karyawan (Studi Pada Karyawan Perum Jasa Tirta I Malang Jawa Timur). Jurnal Administrasi Bisnis. 14(1), hal.1-10.

Rahimic, Zijada. (2013). Influence Of Organizational Climate on Job Satifaction in Bosnia and Herzegovina Compaines. International Business Research. 6(1), pp.129-139.

Ratna Sari, Nita., Moehammad Soe'oed Hakam., dan Heru Susilo. (2015). Pengaruh Kepuasan Kerja Terhadap Turnover Intention (Studi Pada AJB 
Bumiputera 1912 Kantor Wilayah Jatim II/Malang). Jurnal Administrasi Bisnis. 27(1), hal.1-8.

Rini, Dyah P., Rusdarti, Suparjo. (2013). Pengaruh Komitmen Organisasi, Kepuasan Kerja, dan Budaya Organisasi terhadap Organizational Citizenship Behavior (OCB) (Studi pada PT, Plasa Simpanglima Semarang). Jurnal Ilmiah Dinamika Ekonomi dan Bisnis. 1(1), pp.2237.

Salleh, R., Mishaliny S. N. And Haryani H. (2012). Job Satisfaction, Organizational Commitment and Turnover Intention: A Care Study on Employess of a Retail Company in Malaysia. World Academy of Science, Enginering and Technology. 6(12). pp.316-322.

Suhanto, Edi, (2009). Pengaruh Stres Kerja dan Iklim Organisasi terhadap Turnover Intention dengan Kepuasan Kerja sebagai Variabel Intervening, Studi di Bank Internasional Indonesia, Tesis. Universitas Diponegoro.

Suliman, AM., and Obaidli, H.A. (2011). Organizational climate and turnover in Islamic banking in the UAE. International Journal of Islamic and Middle Eastern Finance and Management. 4(4), pp.308-324.

Suryani, Ratna. (2011). Analisis Pengaruh Persepsi Dukungan Organisasi terhadap Turnover intentions dengan Peran Komitmen Keorganisasian sebagai Mediasi. Tesis. Jakarta: Fakultas Ilmu Sosial Politik Departemen Ilmu Administrasi Program Pasca Sarjana Universitas Indonesia

Susanty, Etty. (2012). Pengaruh Iklim Organisasi terhadap Kepuasan Kerja dan Komitmen Pegawai pada Universitas Terbuka. Jurnal Organisasi dan Manajemen. 8(2), hal.121-134.

Tadampali, Andi Caesar To, Abdurrahman Hadi dan Rudi Salam. (2016). Pengaruh Iklim Organisasi Terhadap Turnover intention Melalui Kepuasan Kerja Sebagai Variabel Intervening Pada PT. Bank Sulserbar. Jurnal Administrasi Publik. 6(2). hal.36-46.

Teh, Goi Mei. (2014). Impact of Organizational Climate on Intentions to Leave and Job Satisfaction. World Journal of Management. 5(2), pp.14 - 24.

Turkmilyaz, Ali, Akman Gulsen, Ozkan Coskun \& Pastuak Zbigniew. (2011). Empirical Study of Public Sector Employee Loyalty and Satisfaction. Industrial Management \& Data Systems. 111(5), pp.675-696.

Utama, Suyana M. (2014). Aplikasi Analisis Kuantitatif Bagian Kedua. Denpasar: Sastra Utama.

Wirawan. (2009). Manajemen Sumber Daya Manusia. Bandung: CV. Alfabeta. 
E-Jurnal Manajemen, Vol. 8, No. 1, 2019: 7283 - 7311

Witasari, Lia. (2009). Analisis Pengaruh Kepuasan Kerja dan Komitmen Organisasional Terhadap Turnover Intentions Studi Empiris Pada Novotel Semarang. Tesis. Universitas Diponegoro Semarang.

Yücel, I. (2012). Examining the relationships among job satisfaction, organizational commitment, and turnover intention: an empirical study. International Journal of Business and Management. 7(7), pp.44-61.

Zhao, Erdong and Liwei Liu. (2010). Comments of Development of Job Embeddednes About Study to Trunover and Exploration Into Application in Enterprises. Asian Social Science. 6(6)pp.63-64. 